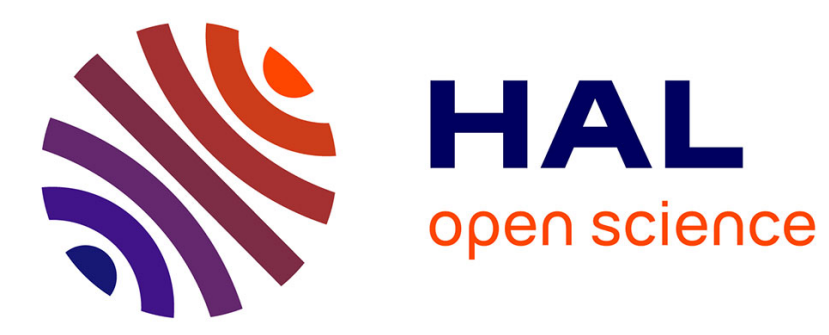

\title{
Comparative analysis of olfactory learning of Apis cerana and Apis mellifera
}

\author{
Zhengwei Wang, Ken Tan
}

\section{To cite this version:}

Zhengwei Wang, Ken Tan. Comparative analysis of olfactory learning of Apis cerana and Apis mellifera . Apidologie, 2013, 45 (1), pp.45-52. 10.1007/s13592-013-0228-3 . hal-01234705

\section{HAL Id: hal-01234705 \\ https://hal.science/hal-01234705}

Submitted on 27 Nov 2015

HAL is a multi-disciplinary open access archive for the deposit and dissemination of scientific research documents, whether they are published or not. The documents may come from teaching and research institutions in France or abroad, or from public or private research centers.
L'archive ouverte pluridisciplinaire HAL, est destinée au dépôt et à la diffusion de documents scientifiques de niveau recherche, publiés ou non, émanant des établissements d'enseignement et de recherche français ou étrangers, des laboratoires publics ou privés. 


\title{
Comparative analysis of olfactory learning of Apis cerana and Apis mellifera
}

\author{
Zhengwei $\mathrm{WANG}^{1,2}$, Ken $_{\text {TAN }}{ }^{1,2}$ \\ ${ }^{1}$ Plant Protection College, Yunnan Agricultural University, Kunming 650201, China \\ ${ }^{2}$ Key Laboratory of Tropical Forest Ecology, Xishuangbanna Tropical Botanical Garden, Chinese Academy of \\ Science, Kunming 650223 Yunnan Province, China
}

Received 23 March 2013 - Revised 30 June 2013 - Accepted 15 July 2013

\begin{abstract}
The Eastern honeybee, Apis cerana, is indigenous to Asia and is an important pollinator for Asian ecosystems; the Western honeybee, Apis mellifera, has been introduced to Asia because of its high honey yields. These two species are now sympatric and share a similar environment. Whether learning in $A$. cerana can be studied using the proboscis extension response paradigm, as developed for A. mellifera, is still unexplored. Here, we investigate $A$. cerana's associative olfactory learning with three different odors (hexanal, nonanal, and geraniol) and compared it with the learning performances of $A$. mellifera. After an acquisition phase, the bees were tested to determine whether they discriminated between the experienced odors (an odor paired with a reward during acquisition) from non-experienced odors (an odor not paired with a reward during acquisition). During the acquisition phase, A. mellifera showed higher learning scores than A. cerana. However, there was no statistical difference between the two species in the retention phase. Both species discriminated an experienced odor from a non-experienced odor. Our results suggested that A. cerana is equally amenable to the study of learning using the proboscis extension response paradigm supporting the behavioral evidence for future olfactory learning research with $A$. cerana.
\end{abstract}

\section{Apis cerana / olfactory learning / proboscis extension response}

\section{INTRODUCTION}

The Western honeybee, Apis mellifera, is well established as a model for studying olfactory learning using a classical association assay. This assay is based on the powerful Pavlovian conditioning protocol, the proboscis extension response (PER; Bitterman et al. 1983; Giurfa and Sandoz 2012; Matsumoto et al. 2012). In PER conditioning, a hungry bee is first exposed to a conditioned stimulus (CS; such as an odor, color, or texture) followed by gently touching the bee's antennae with unconditioned stimulus (US) that elicits proboscis extension response; US was then delivered to the proboscis.

Corresponding author: K. Tan, kentan@xtbg.ac.cn Manuscript editor: Bernd Grünewald
If the bee responds with proboscis extension when presented with CS, this suggests that the bee has learned of the association (Bitterman et al. 1983).

Recently, PER assays have been used to investigate the learning ability of other bee species. Some have proved amenable to the use of PER, such as Vespula wasps (Vorel and Pitts-Singer 2010) and the red dwarf honey bee $A$. florea (Kaspi and Shafir 2013). Conversely, PER has proved to be an ineffective tool for some species such as the stingless bee Scaptotrigona deplis (Mc Cabe et al. 2007) and solitary species of megachilides (Osmia lingnaria, Megachile rotundata, and Megachile pugnata; Vorel and Pitts-Singer 2010).

A. mellifera and Apis cerana have evolved in distinct ecologies; their social organization as well as mating behavior has been successfully shaped by their respective ecosystems. A. mellifera was 
introduced in China in the 1920s for its high productivity (Yang 2005) and now live sympatric with A. cerana in Asia. A. cerana was smaller in body size than $A$. mellifera and also showed stronger merits in resisting bee mites (Peng et al. 1987), hornets (Tan et al. 2012a, b), and extreme climates (Tan et al. 2012a, b). Studies utilizing color and grating patterns to investigate learning differences between these two species suggested that $A$. cerana perform as well as $A$. mellifera (Qin et al. 2012). However, the role of olfaction in learning in $A$. cerana is still unknown. Here, we aim to (a) determine whether $A$. cerana workers can be used to study learning applying the classic PER conditioning paradigm, (b) investigate the olfactory learning ability of $A$. cerana, and (c) compare this ability with olfactory associative learning of $A$. mellifera.

\section{MATERIALS AND METHODS}

Three A. cerana and three A. mellifera test colonies were set up at an apiary of the Eastern Bee Research Institute, Yunnan Agricultural University, Kunming, China. All colonies were queenright and housed in standard Langstroth hives. Before we started our experiments, we equalized the colonies such that each contained four frames covered with adult workers and at least two frames of brood and two frames of honey and pollen.

Olfactory conditioning experiments were conducted between May and July 2012. We blocked the entrances to the hives and collected 20 returning foragers (nectar foragers but not pollen foragers) from each colony per trial. These bees were transferred to the laboratory and narcotized on ice. The bees were harnessed in $0.5-\mathrm{ml}$ plastic centrifuge tubes which had the bottoms cut out according to the head sizes of $A$. cerana and A. mellifera, respectively (Figure 1). Thus, the bees were restrained in such a way that they were still able to move their heads and proboscis. The bees were fed $10 \mu \mathrm{L}$ of $2 \mathrm{M}$ sucrose solution and placed in an incubator $\left(20^{\circ} \mathrm{C}\right.$ and $\left.65 \% \mathrm{RH}\right)$ overnight. The next morning, we trained all surviving bees to associate an odor with a sucrose reward using the PER procedure (Bitterman et al. 1983). Prior to training, we tested the bees and discarded any that showed no PER to sugar solution (unconditioned stimulus) or showed PER to air flow carrying a test odor.
Odors were delivered to the bees from three parallel $20-\mathrm{mL}$ syringes mounted on a training station. One of the syringes contained only filter paper to deliver air flow as continuous stream. In the other two syringes, $2 \mu \mathrm{L}$ of each pure odor, hexanal (98\%; Sigma-Aldrich, Co., St. Louis, USA), nonanal (98 \%; Sigma-Aldrich), and geraniol (96\%; Sigma-Aldrich, Co) was placed on a strip of filter paper $(5 \times 5 \mathrm{~mm})$ inside each syringe. The tip of the syringe was placed $1.5 \mathrm{~cm}$ from the bees' head, while a valve was attached to the other end along with a Y-shaped tube, silicon tube, and air pump. An air stream exhaust system was formed by a $10-\mathrm{cm}$ diameter tube that was placed $12 \mathrm{~cm}$ behind the bee.

For proboscis extension response experiments, bees were exposed to a constant flow of clean air for $35 \mathrm{~s}$, and then to a flow containing a particular odor for $6 \mathrm{~s}$ (CS). Three seconds after the odor stimulus onset, we touched the test bee's antennae with a toothpick soaked in sucrose solution for $3 \mathrm{~s}$. Bees showing proboscis extension in the first $3 \mathrm{~s}$ after exposure to the odors were recorded as 1 ; those that did not were recorded as 0 . In the acquisition phase, each bee was trained for six conditioning trials sequentially at an inter-trial interval of $10 \mathrm{~min}$. We performed retention tests $24 \mathrm{~h}$ after the acquisition phase by presenting only the particular odor. The response of each bee was tested with a pair of odors; the first was the one experienced during the acquisition phase (represented by a CS), followed by a novel odor (represented by non-experienced odors (NOd); Matsumoto et al. 2012), which were tested for bees' CS-specific memory. The following CS/NOd pairs were established: $\mathrm{CS}_{\text {hexanal }} / \mathrm{NOd}_{\text {nonanal }}, \mathrm{CS}_{\text {nonanal }} /$ $\mathrm{NOd}_{\text {geraniol }}, \mathrm{CS}_{\text {geraniol }} / \mathrm{NOd}_{\text {hexanal. }}$. The procedure was repeated with hexanal, nonanal, and geraniol as CSs to test for any odor bias in both A. cerana and $A$. mellifera. The number of tested bees for hexanal, nonanal, and geraniol odor of A. cerana were 39, 43, and 53 , respectively, while the number of tested bees of $A$. mellifera were 57, 45, and 48, respectively.

To determine if the learning abilities of $A$. cerana and $A$. mellifera was affected by their hunger motivation, the gustatory responsiveness was measured in each individual of $A$. cerana $(n=64)$ and $A$. mellifera $(n=64)$. One hour after mounting in the tube, each individual was first stimulated with a droplet of water and then with the following sucrose solutions offered in ascending order: $0.1,0.3,1,3,5$, 


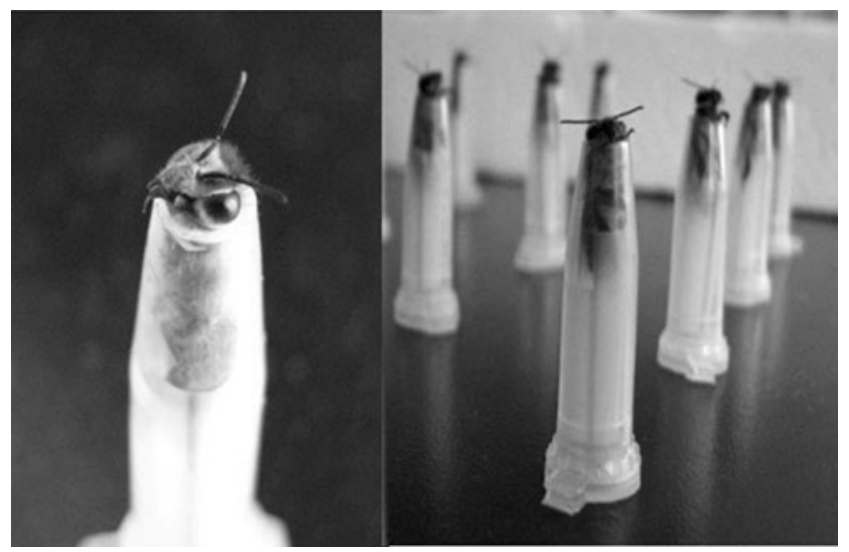

Figure 1. Tethered bees in plastic tube so that their heads and proboscises could move freely.

10, and $30 \%$ to test its PER. The interstimulus interval was about $2 \mathrm{~min}$ to exclude sensitization effects (modified from Scheiner et al. (2005).

\subsection{Statistics}

Data were recorded as the proportion of bees exhibiting PER of the total number of bees for each species and odor. This data were analyzed with a repeated measures ANOVA, using trials as the within-subject effect and bee species (A. cerana and A. mellifera) and CSs (hexanal, nonanal, and geraniol) as the between-subject effect, respectively. We performed Mauchly's test for sphericity to ensure that the assumption of sphericity was not violated. We used post hoc tests (least significant differences) to determine if there were differences between the two species.

Paired $T$ tests were used to determine if there were differences of the retention scores between $A$. cerana and $A$. mellifera for experienced odors (CS pairing with reward, $\mathrm{CS}_{\text {hexanal }}, \mathrm{CS}_{\text {nonanal, }}$ and $\mathrm{CS}_{\text {geraniol }}$ ) and NOd, which pairing without any reward during acquisition phase $\left(\mathrm{NOd}_{\text {hexanal }}, \mathrm{NOd}_{\text {nonanal }}\right.$ and NOd $_{\text {geraniol, }}$ respectively).

The different gustatory responsiveness was analyzed with chi-square tests between $A$. cerana and $A$. mellifera to every different sucrose concentrations. All calculations were performed with SPSS Statistics 17.0 (www.spss-china.com).

\section{RESULTS}

In A. cerana, bees are able to associate an odor with reward. PER scores rose from $0 \%$ to nearly $60 \%$ for hexanal, a significant increase (repeated measures ANOVA, $F=36.314, d f=5, P<0.001$ ). For nonanal and geraniol, learning scores also increased significantly with number of trials (repeated measures ANOVA, $F=3.503, d f=10, P<$ 0.001 ). There were no significant differences in the abilities of bees to learn a conditioned response to each of the three different odors (CSs effect: $F=$ $0.92, d f=2, P=0.401$; Figure 2).

However, there were some differences of bees in odor response in the first three trials, while after six training trials, about $60 \%$ of bees responded to all of the odors (trial 2: $F=$ 9.09, $d f=2, P<0.001$; trial $3: F=5.59, d f=2, P=$ 0.005 ; trial $4: F=0.39, d f=2, P=0.675$; trial 5: $F=0.75, d f=2, F=0.472$; trial $6: F=0.17, d f=2$, $P=0.841$; Figure 2).

Retention tests showed that for A. cerana, responses to experienced odors were significantly higher than for non-experienced odors $\left(\mathrm{CS}_{\text {hexanal }} /\right.$ $\mathrm{NOd}_{\text {nonanal }}$ : $T=4.42, d f=38, P<0.001 ; \mathrm{CS}_{\text {nonanal }}$ $\mathrm{NOd}_{\text {geraniol }}: T=6.04, d f=42, P<0.001 ; \mathrm{CS}_{\text {geraniol }}$ NOd $\left._{\text {hexanal }}: T=5.21, d f=52, P<0.001\right)$. No statistical difference was found for hexanal, nonanal, and geraniol in either the experienced $(F=0.6, d f=$ 2, $P=0.55)$ or the non-experienced group $(F=1.57$, $d f=2, P=0.213)$. 


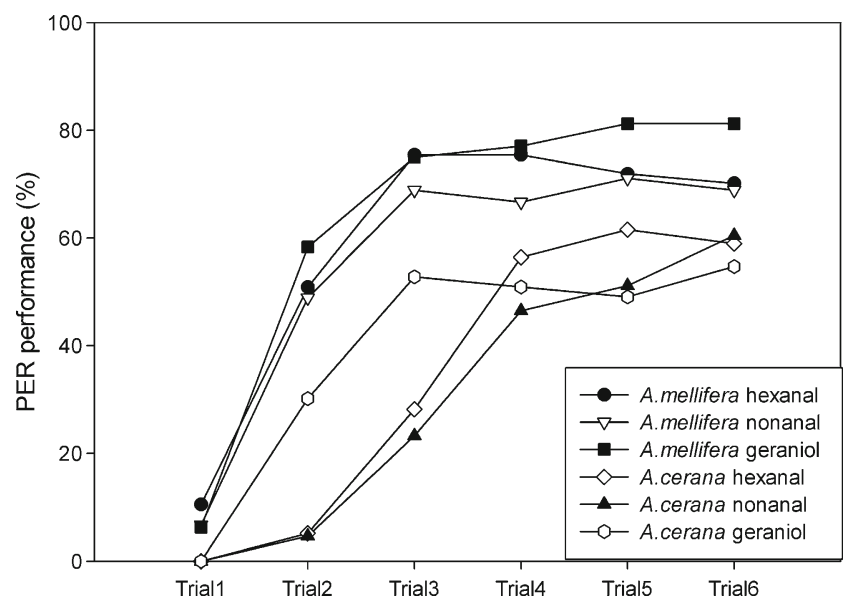

Figure 2. Acquisition of olfactory conditioning in A. cerana and A. mellifera in response to hexanal, nonanal, and geraniol, respectively. The purple, dark blue, and the light blue lines represent $A$. mellifera's acquisition function for hexanal $(n=57)$, nonanal $(n=45)$, and geraniol $(n=48)$, with a sucrose reward, respectively. The green, yellow, and orange lines represent the same for A. cerana's for hexanal $(n=39)$, nonanal $(n=43)$, and geraniol $(n=53)$ with sucrose reward respectively.

A. mellifera also showed a significant increase in learning scores during the acquisition phase ( $F$ $=95.792, d f=5, P<0.001)$. However, A. mellifera showed significantly higher learning scores than A. cerana did $(F=39.635, d f=1, P<0.001$; Figure 2, Table I).

Both A. cerana and A. mellifera showed high retention scores (up to $60 \%$ ) after $24 \mathrm{~h}$ of training. There were no significant difference between these two bee species to $\mathrm{CS}_{\text {hexanal }} / \mathrm{NOd}_{\text {nonanal }}$ pair (hexanal: $F=0.91$, $d f=1, P=0.343$; nonanal: $F=0.37, d f=1, P=$ 0.546). Similar results were obtained for $\mathrm{CS}_{\text {nonanal }} / \mathrm{NOd}_{\text {geraniol }}$ pair (nonanal: $F=0.36$, $d f=1, P=0.551$; geraniol: $F=0.45, d f=1, P=$ 0.505 ) and in $\mathrm{CS}_{\text {geraniol }} / \mathrm{NOd}_{\text {hexanal }}$ (geraniol: $F=1.39, d f=1, P=0.242$; hexanal: $F=0.26$, $d f=1, \quad P=0.873$; Figure 3$)$. There was an increase in response to the last conditioning trial and the retention test in both species; however, there was no statistic significant in nonanal and geraniol. There was a decline even been found when A. mellifera learnt of geraniol. That is may be because geraniol was the component of Nasonov pheromone (Table II).
A. mellifera bees were more responsive to low sucrose concentrations $(0.3 \%: \chi 2=6.81, P$ $=0.009 ; 1 \%: \chi 2=8.003, P=0.005$ and $3 \%: \chi 2$ $=6.817, P=0.009)$ than $A$. cerana bees, while there were no significantly statistical differences in water, $0.1 \%$ sucrose group and $5 \%$ and other two high concentration groups (Figure 4).

\section{DISCUSSION}

Our results show that the classical PER conditioning can be applied to A. cerana. Twenty-four-hour retention scores of $A$. cerana were similar to those of $A$. mellifera. However, $A$. cerana's PER acquisition scores were lower than those of $A$. mellifera after six trials (Figure 2). Several other bee species are known to be amenable to the PER paradigm such as the stingless bees Melipona quadrifasciata (Vorel and Pitts-Singer 2010) and eusocial Vespula wasps (Vorel and Pitts-Singer 2010). Among Apis, learning performance was only wellstudied in different subspecies of A. mellifera, with only one study performed on A. florea (Kaspi and Shafir 2013). Our findings suggest 
Table I. Repeated measures ANOVA on the effect of species (A. cerana and A. mellifera) during acquisition of three odors (hexanal, nonanal, and geraniol), respectively, and on conditioned PER.

\begin{tabular}{lrrrr}
\hline & $d f$ & MS & F & \multicolumn{1}{c}{$P$} \\
\hline Between subjects & & & & $<0.001$ \\
Species & 1 & 24.077 & 39.635 & 0.202 \\
CSs & 2 & 0.978 & 1.609 & 0.998 \\
Species $\times$ CSs & 2 & 0.001 & 0.002 & \\
Error & 279 & 0.607 & & $<0.001$ \\
Within subjects & & & & $<0.001$ \\
Trials & 3.466 & 24.135 & 170.115 & 0.033 \\
Trials $\times$ species & 3.466 & 1.605 & 2.196 & 0.012 \\
Trials $\times$ CSs & 6.932 & 0.312 & 2.593 & \\
Trials $\times$ species $\times$ CSs & 6.932 & 0.368 & & \\
Error & 967.075 & 0.142 & & \\
\hline
\end{tabular}

The assumption of sphericity was violated (Mauchly's test: $W=0.353, X^{2}=288.286, d f=14, P<0.001$ ), so the results are reported with the Greenhouse-Geisser correction to degrees of freedom
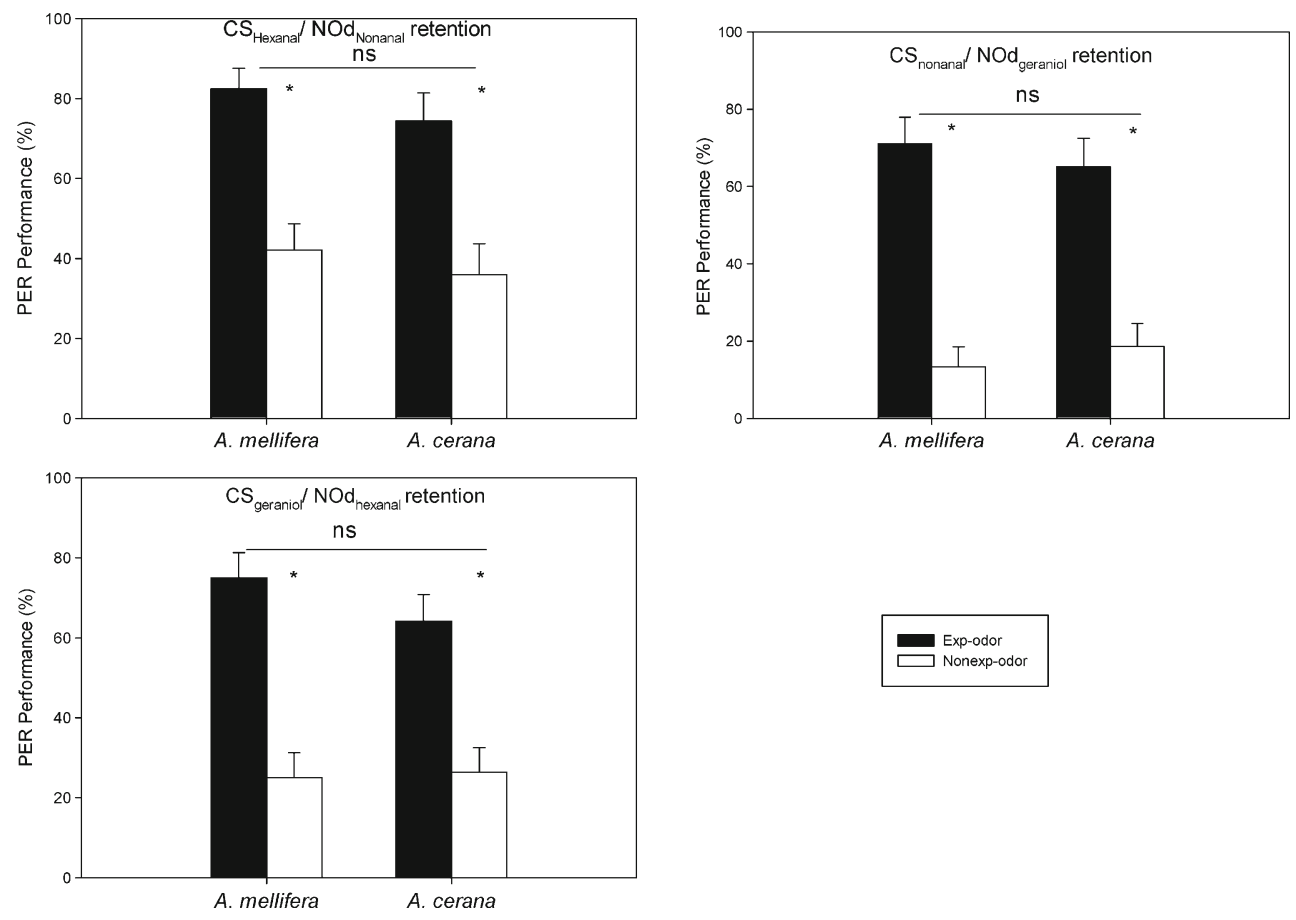

Figure 3. Mean retention scores ( $\pm \mathrm{SD}$ ) of $A$. cerana and A. mellifera for experienced and non-experienced odors. To eliminate odor bias, hexanal paired with a reward during the acquisition phase $\left(\mathrm{CS}_{\text {hexanal }}\right)$ was compared with the non-experienced odor $\left(\mathrm{NOd}_{\text {nonanal }}\right)$. The $\mathrm{CS}_{\text {nonanal }}$ group was also compared with $\mathrm{NOd}_{\text {geraniol }}$ group, while the $\mathrm{CS}_{\text {geraniol }}$ group compared with $\mathrm{NOd}_{\text {hexanal }}$. Odors paired with the reward were termed as experienced odors (brown), while those not paired with the reward were termed as non-experienced odors (dark yellow). 
Table II. The retention scores between last training trial and the retention trail in both A. mellifera and A. cerana.

\begin{tabular}{|c|c|c|c|c|c|c|c|c|}
\hline & \multicolumn{4}{|c|}{ A. mellifera } & \multicolumn{4}{|l|}{ A. cerana } \\
\hline & Last trial & Retention & $\chi^{2}$ & $P$ & Last trial & Retention & $\chi^{2}$ & $P$ \\
\hline Hexanal & 70.18 & 82.46 & 3.947 & 0.047 & 59 & 74.36 & 5.05 & 0.025 \\
\hline Nonanal & 68.89 & 71.11 & 0.095 & 0.758 & 60.5 & 65.12 & 0.455 & 0.5 \\
\hline Geraniol & 81.25 & 75 & 1.049 & 0.306 & 54.7 & 64.15 & 1.681 & 0.195 \\
\hline
\end{tabular}

that $A$. cerana is also amenable to PER conditioning. Thus, A. cerana may also be of use as a model organism for physiological and neurobiological research.

The paradigm we have used to compare learning and memory in these two Apis species relies on the fact that a hungry bee reflexively extends its proboscis in response to sucrose stimulation of the antennae and associates an odor stimulus with the sucrose reward. Associative learning under these conditions is usually rapid with successful acquisition within few trials of forward pairing (Bitterman et al. 1983). Memory is formed in a trial- and timedependent manner indicating processes of memory consolidation that can be traced to particular regions of the bee brain and to molecular and cellular processes (Menzel 1999, 2012; Giurfa
2007; Giurfa and Sandoz 2012). Acquisition and retention depend on many parameters, e.g., the state of satiation reflecting the motivation of the animal and the reward value of a particular concentration of sucrose solution (Erber et al. 1980). Here, we still cannot exclude the possibility that rather unspecific parameters could have also influenced our experiments. For example, the two species may have had differing abilities to adapt to the confined test conditions or may have required different amounts of food in order to achieve satiation meaning that the reward value of the sucrose solution could have been different for each species.

A. cerana had lower PER scores than $A$. mellifera in the first three trials of the acquisition phase, suggesting that it is a slow learner. This may be because the strain of $A$. mellifera

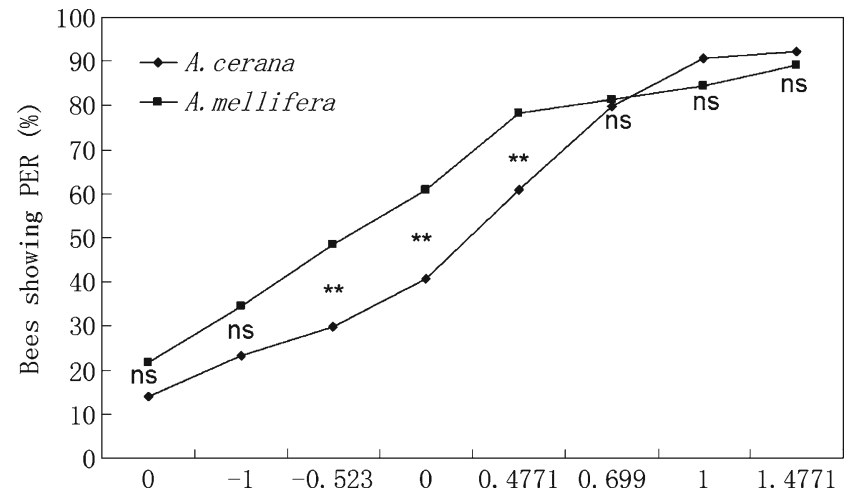

Figure 4. Gustatory responsiveness between A. cerana (blue line) and A. mellifera (pink line). The $x$-axis shows the water stimulation ( 0 ) and the logarithm of the sucrose concentrations tested. The $y$-axis gives the percentage of bees showing the proboscis extension response (PER). Star marks $(* * P<0.01)$ indicated significant differences, ns presented no significant difference. 
that was introduced in China has been subjected to intense artificial selection to be more docile, while the $A$. cerana we utilized were managed in a half wild situation. Thus, these two bee species could have different reactions to harnessing. Yang (2009) reported even though there are overlaps on its niche between $A$. cerana and $A$. mellifera, these two species have its own properties to reduce the food competition. A. cerana is adept in collecting sporadic nectar flowers, while A. mellifera exploits large flower fields. In dearth period, we always can see that $A$. mellifera colonies are shorter of nectar than $A$. cerana colonies when they are kept in a constant place. This may indicate that $A$. cerana can better use the little patches near the hives than $A$. mellifera do. A. cerana always meet the lower selective pressure to learn associations between odors and rewards. This may be one reason why $A$. cerana performed worse than $A$. mellifera during their acquisition phase.

After acquisition, there was no significant difference between these two sibling species in memory retention of different odors. Both species discriminated between the experienced odor and non-experienced odor. These results are consistent with previous studies on odor learning and odor discrimination in bees (Bitterman et al. 1983; Menzel 1999).

We conclude that $A$. cerana is amenable to be studied using classic olfactory PER assay. However, further work is required to unveil the physiology of the olfactory learning mechanism based on this behavioral study.

\section{ACKNOWLEDGMENTS}

We respect all three anonymous reviewers' very valuable comments and great help for the manuscript revision. We thank Michael J. Holmes for English polishing and comments. This work was supported by the China National Research Fund (31260585) and by the Key Laboratory of Tropical Forest Ecology, Xishuangbanna Tropical Botanical Garden, Chinese Academy of Science.
Analyse comparative de l'apprentissage olfactif d'Apis cerana et d'Apis mellifera

Apis cerana / apprentissage / olfaction / REP / réflexe d'extension du proboscis

Vergleich des olfaktorischen Lernens von Apis cerana und Apis mellifera

Apis cerana / Apis mellifera / Duftlernen / Rüsselreflex

\section{REFERENCES}

Bitterman, M., Menzel, R., Fietz, A., Schäfer, S. (1983) Classical conditioning of proboscis extension in honeybees (Apis mellifera). J. Comp. Psychol. 97(2), 107-119

Erber, J., Masuhr, T., Menzel, R. (1980) Localization of short term memory in the brain of the bee, Apis mellifera. Physiol. Entomol. 5(4), 343-358

Giurfa, M. (2007) Behavioral and neural analysis of associative learning in the honeybee: a taste from the magic well. J. Comp. Physiol. A 193, 801-824

Giurfa, M., Sandoz, J.C. (2012) Invertebrate learning and memory: fifty years of olfactory conditioning of the proboscis extension response in honeybees. Learn. Mem. 19(2), 54-66

Kaspi, R., Shafir, S. (2013) Associative olfactory learning of the red dwarf honey bee Apis florea. Apidologie 44(1), 100-109

Matsumoto, Y., Menzel, R., Sandoz, J.C., Giurfa, M. (2012) Revisiting olfactory classical conditioning of the proboscis extension response in honey bees: a step towards standardized procedures. J. Neurosci. Methods 211, 159-167

Mc Cabe, S., Hartfelder, K., Santana, W., Farina, W. (2007) Odor discrimination in classical conditioning of proboscis extension in two stingless bee species in comparison to Africanized honeybees. J. Comp. Physiology A: Neuroethol. Sens. Neural. Behav. Physiol. 193(11), 1089-1099

Menzel, R. (1999) Memory dynamics in the honeybee. J. Comp. Physiology A: Neuroethol. Sens. Neural. Behav. Physiol. 185(4), 323-340

Menzel, R. (2012) The honeybee as a model for understanding the basis of cognition. Nature Rev. Neurosci. 13, 758-768

Peng, Y.-S., Fang, Y., Xu, S., Ge, L. (1987) The resistance mechanism of the Asian honey bee, Apis cerana Fabr., to an ectoparasitic mite, Varroa jacobsoni Oudemans. J. Invertebr. Pathol. 49(1), 54-60 
Qin, Q.H., He, X.J., Tian, L.Q., Zhang, S.W., Zeng, Z.J. (2012) Comparison of learning and memory of Apis cerana and Apis mellifera. J. Comp. Physiol. A: Neuroethol. Sens. Neural. Behav. Physiol. 198(10), $777-8$

Scheiner, R., Kuritz-Kaiser, A., Menzel, R., Erber, J. (2005) Sensory responsiveness and the effects of equal subjective rewards on tactile learning and memory of honeybees. Learn. Mem. 12(6), 626635

Tan, K., Wang, Z., Li, H., Yang, S., Hu, Z., Kastberger, G., Oldroyd, B.P. (2012a) An 'I see you' preypredator signal between the Asian honeybee, Apis cerana, and the hornet, Vespa velutina. Anim. Behav. 83(4), 879-882
Tan, K., Yang, S., Wang, Z.W., Radloff, S.E., Oldroyd, B.P. (2012b) Differences in foraging and broodnest temperature in the honey bees Apis cerana and $A$. mellifera. Apidologie 43(6), 618-623

Vorel, C.A., Pitts-Singer, T.L. (2010) The proboscis extension reflex not elicited in megachilid bees. J. Kansas Entomol. Soc. 83(1), 80-83

Yang, G.H. (2005) Harm of introducing the western honeybee Apis mellifera L. to the Chinese honeybee Apis cerana F. and its ecological impact. Acta Entomol. Sin. 48, 401-406 (In Chinese)

Yang, G.H. (2009) Chinese honeybee Apis cerana F. influence on Chinese forestry ecological system. Apic. China 60, 5-10 (In Chinese) 